\title{
Competence and innovative, humanistic education as the basis of sustainable development of the modern world
}

\author{
Vasil Khiminets ${ }^{1}$, Marianna Ostrovska ${ }^{2 *}$, and Alexander Ostrovsky ${ }^{3}$ \\ ${ }^{1}$ Transcarpathian Institute of Postgraduate Pedagogical Education, A. Voloshyna str., Uzhgorod, \\ Ukraine \\ ${ }^{2}$ Ferenc Rakoczi II Transcarpathian Hungarian College of Higher Education Ukraine, 6 Kossuth \\ square, Beregovo, Ukraine \\ ${ }^{3}$ Mukachevo State University, 26 Uzhgorod Street, Mukachevo, Ukraine
}

\begin{abstract}
The article deals with topical issues of interaction between human and natural systems and the role of education in these processes Attention is focused on the fact that the further development of society oriented only increase production capacity and meet its consumers' interests, does not meet the laws of nature and leads to the destruction of humanity. This is due to the fact that the pressure of human society on the environment is growing, and the capacity of natural ecosystems is limited. It is shown that the basis of the nature-consuming philosophy of mankind must be changed to a new ecological and economic worldview, in which social development must acquire a humanistic and ecological orientation. Natural resources in such a scheme should be viewed not only as a means of development of productive forces, but also as a factor in the environment in which mankind lives. The main role in the implementation of goals of sustainable development in a given area of the modern urban world is given to changing the paradigm of the educational process, its reorientation from the mechanical transfer of knowledge to the formation of professional competencies, innovation and humanistic worldview.
\end{abstract}

\section{Introduction}

The authors of many modern studies on the study, analysis and forecasting of vectors and directions of human development argue that the increase in production capacity, their energy and raw material needs, has led to an exponential increase in the amount of natural products extracted from modern Earth. This problem is complicated by the demographic situation and the formed consumer philosophy of the majority of the population. This has led to major problems with renewable and non-renewable, primarily energy resources, for the distribution and use of which is a fierce struggle on the planet. This has led to major problems with renewable and non-renewable, primarily energy resources, for the distribution and use of which is a fierce struggle on the planet.

\footnotetext{
* Corresponding author: marianna.29.1984@gmail.com
} 
Analysis of the problems and processes of destruction of the world created by mankind shows that one of the main causes of global crises is the general low level of culture and education of the population on these issues around the world.

The relevance of the study is that the implementation of the ideas and principles of sustainable development requires the formation of a new public culture and critical thinking, new educational models, new educational content, changing the educational mission as a whole.

It is shown that the change of the knowledge paradigm of education to competence, reorientation of the educational process from mechanical knowledge transfer to the formation of innovative and humanistic worldview in the young generation and the introduction of blue economy, will translate the ideas of sustainable society into practice.

\section{Results}

In the history of mankind can be divided into three periods, which characterized by certain relationships of society with the environment: the first -man slowly changes and transforms nature, but comprehensively depends on it; the second - the changed nature prevails, but the person is convinced that it can use it indefinitely; third - nature changes very quickly and irreversibly, systematically occur large-scale natural disasters, man-made accidents, problems with the feasibility of human existence. In accordance with the priorities of these periods are changing and fundamental educational concepts, including such as mission, purpose and goals of education, which is always accompanied by the emergence of new paradigms in the educational process [1, p.244-246].

These changes gained great momentum in the late twentieth and early twenty-first century, when, for the first time in human history, there was a combination of two unique mental and man-made phenomena of man - scientific and technological progress and globalization. As a result of the combination of these processes, humanity has received an infinite number of unexpected problems, in particular such as:

- developed regions of the world began to lack renewable and non-renewable natural resources (food, minerals, arable land, water, air, etc.) required for the continuous operation of production facilities;

- climate change, attack on the world community of natural disasters (earthquakes, tsunamis, storms, floods, landslides, etc.) and man-made accidents, the intensification of known and allegedly overcome by man in the past and the constant emergence of new diseases (SARS, tuberculosis, tuberculosis, covid, etc.);

- the formation of many peoples of the world an average consumer philosophy of life (the average person needs a lot, at once and in large quantities, and needs increase over time).

Modern educated man, endowed with the ability to think, analyze, predict, subdue and, to a large extent, forced all natural ecosystems to work for their needs, ruthlessly exhausting their resources and opportunities to expand energy and, consequently, environmental and economic spheres. Humans on a global scale have been the main cause of the loss of balance between natural life support systems and the industrial, technological and demographic needs of urban society.

The main reasons that led to such a critical situation should be considered: finiteness, the size of the planet Earth, the demographic situation, urban lifestyle and, as a consequence, the continuous increase in human pressure on nature.

Education, as an institution responsible for the formation of an appropriate worldview in the younger generation, has developed in a large part of the world's population an irresistible desire to "live better tomorrow than today." 
The latter, with today's vectors of society's development, can be realized only under the condition of continuous growth of the use of natural energy and raw materials - air, water, food, energy, etc. Scientists have estimated that to meet all the needs of the average person a hundred years ago from the bowels of the Earth extracted about 0.5 tons of various raw materials. To meet all the needs of one person today, it is already necessary to extract 27.5 tons of various minerals from the bowels of the Earth. At the beginning of the twentieth century, the planet was inhabited by 1.2 , and today - almost 8 billion people. In order for the current civilization to live one year from the bowels of the Earth, it is necessary to extract about 200 billion tons of raw materials. A simple calculation shows that the capacity of human community to intervene in the bowels of the Earth over the past hundred years has increased three hundred times. Leading such an urban way of life, humanity has sunk into the Earth for 1.5-2.0 km, created large voids here - artificial ecosystems, which began to interact with natural ecosystems and cause various cataclysms (storms, tsunamis, earthquakes, etc.). In addition, the technologies used by the current civilization in various industries, together with raw materials use very large amounts of energy, and in useful things, convert only $10-20 \%$ of the extracted raw materials, the rest goes to waste, which recently occupy large areas of modern countries and affect the purity of air, water and the environment. The main part of energy humanity receives in the process of burning organic and inorganic substances, which again requires a significant amount of raw materials and produces a lot of waste. In general, one person leading an urban way life, in one year produces about 27.5 tons of various types of waste - industrial, street and household. According to various estimates, the amount of artificial energy capacity on the planet has already reached almost $0.03 \%$ of the amount of energy that the Earth receives from space. These are already commensurate values, their ratio began to affect the heat exchange of the planet and space [2, p.36-38]. It should be realized that the further development of society, focused only on the growth of production capacity and satisfaction of its consumer interests, does not comply with the laws of nature and leads to the destruction of humanity and the planet as a whole. The problem is complicated by the fact that in order for humanity in ten years to have an environmental situation equivalent to today, in global projects to maintain clean air, water, food need to invest about 30 trillion US dollars. These development trends and possible consequences encourage the world community in the last decades of the late XX - early XXI century to think about changing the philosophy of life and look for new ways to develop the world community.

\subsection{Sustainable development}

A possible new approach to human relations with the environment was first announced at the United Nations Conference on Environment and Development (Rio de Janeiro, June 1992). This international conference proposed a new model of rising socio-economic development, which recognizes the right of every person to a dignified life, every country to progress, but at the same time, such a process should exclude irreversible changes in the environment. Before each country and the world as a whole, the proposed model set the task of solving all socio-economic problems without destroying the natural environment and without wasting energy, renewable and non-renewable resources of the planet. The criterion of sustainable development should not be the increase in production, but the potential for its growth in terms of preservation and transition to improving the quality of the environment. In modern interpretations, sustainable development should be considered as a system of innovative interdependent and mutually agreed political, socio-economic, managerial and environmental programs and activities, the main task of which is to meet the needs of society for a dignified life and full development without endangering the lives of future generations [3-6]. 
The authors of many modern studies on the study, analysis and forecasting of vectors and directions of human development argue that the increase in production capacity, their energy and raw material needs, has led to an exponential increase in the amount of natural products extracted from developed countries.

This problem is complicated by the demographic situation and the formed consumer philosophy of the majority of the population. In general, these processes have created a large number of global problems with energy and fossil (renewable and non-renewable) resources. The use and distribution of these resources is currently being fought fiercely around the world.

It is time to change the natural-consumer philosophy of human life, the basis of human activity must be a new look at the relationship of mankind with the environment, new environmental and economic approaches to meeting the needs of the community. Man should recognize the dependence of humanity on the biosphere.

At the end of the last century, economists and practitioners began to develop and implement the ideas of the so-called "green economy". Its essence was that the socioeconomic development of society can occur without significant changes in the environment. To this end, it was proposed to use "recovery technologies" in production cycles, which were to ensure the preservation of energy and raw materials and reduce waste. In practice, it turned out that the green model of socio-economic development is too expensive and does not meet the modern needs of society. The implementation of such a model requires large financial investments, which today can only be done by developed countries [7]. At the same time, large investments in low-waste technologies and the production of less harmful, cleaner goods still use significant energy, are based on extractive industries and produce industrial toxic waste in large quantities.

Later, conducting research and developing new models of the socio-economic systems of the future at the request of the UN, Gunther Pauli proposed an economic model in which production cycles are carried out according to the laws of natural processes, products, profits and environmental benefits. In this model of production activity, the criterion of efficiency, in contrast to traditional economic systems, is not considered to be net profit, but the total environmental and economic effect. This economic philosophy is called the "blue economy" [8]. It is based on the logic of natural processes, their continuity, energy balance and waste-free. The blue economy includes the ideas of the green, it goes beyond just conscious conservation of natural resources. At the heart of the blue economy is not only the protection and preservation of the environment, but also the continuous development of natural ecosystems. This philosophy defends the idea of social justice.

Such a balanced economic system can be realized by reducing or even completely abandoning the use of additional natural resources, energy and costs of waste disposal and recycling. Such savings are created due to the fact that natural ecosystems do not generate waste, because the by-products created in one cycle are used as raw materials in the next, etc. The blue economy uses the principles and models of functioning of natural systems, which can be represented as follows:

- in the processes that create the necessary things, only local resources are used that are environmentally friendly and meet the social needs of the community;

- natural resources are useful and necessary, in all natural processes no new waste is created, all by-products of one process become raw materials for the next and new products;

- in production processes the principle of a cascade of use of energy resources and nutrients which are used for energy creation is applied;

- education and science continuously produces innovations and trains personnel to improve the functioning of production systems of the blue economy. 


\subsection{Education for Sustainable Development (SDD)}

The UN General Assembly prioritizes education among the priorities of sustainable development in the 21 st century. The 21 st Century Agenda states that "education is the foundation of sustainable development" and the main tool for creating a humane and equal society, and the UN ranks education among the three main components of the human development index (along with GDP per capita and life expectancy). Many UN documents outline the tasks and approaches to building the SRF system (most fully in the Decade of Education for Sustainable Development for 2005-2014). In 2014, UNESCO is implementing the Global Program of Action for SRF, which aims to integrate sustainable development into education and education into sustainable development $[4,5]$.

Traditional education, built on the knowledge paradigm, is unable to adequately respond to modern challenges, because: the dynamics of growth of information possessed by mankind and social change are growing rapidly, and knowledge often becomes obsolete before the end of the study period. In addition, Ukraine has not developed a Sustainable Development Strategy, which is required under the "Agenda for the XXI Century" [6].

Under the SRF is understood the educational process aimed at creating scientifically sound knowledge, skills and abilities to form a new ecological and economic social consciousness, a new worldview of people on nature, human place in nature and the nature of their interaction.

This knowledge must be effectively and innovatively communicated to all actors in the lifelong learning process. In these coordinates, humanity must begin to pursue a socially oriented, economically viable and environmentally balanced lifestyle. SRF aims to form an environmentally and economically conscious society in which development is socially desirable, economically viable and environmentally balanced.

The concept of balanced development provides for the reorientation of education in the direction of caring for the environment, abandoning outdated models of production and consumption, harmonizing the development of social, economic and environmental processes. The purpose of the SRF system is the formation and development of continuing education of environmental and economic education throughout life, the formation of the subjects of the educational process consciousness for sustainable development in accordance with the rapidly changing requirements of the XXI century, social, economic and environmental needs of the world, states.

The main thing in the process of implementing the SRF should be learning in action and for action, ie all learners must acquire the knowledge, skills and abilities necessary for action in a sustainable development. It is important to form in people the ability to establish effective interaction between themselves and others, the world in general, to think and act in a non-standard, creative, creative way [9].

Sustainable development is not possible without constant social dialogue, participation of citizens in society, their active position. Sustainable development is not possible without tolerant and intercultural cooperation between peoples of different cultures, religions and political preferences [10-11].

The SRF should be considered as a direction of thinking and activity, both of the individual and of the community as a whole, which determine the modern and immediate existence of human civilization. Education in this process, on the one hand, is a theoretical field of knowledge about the role and place of man in the biosphere, and on the other hand the result and consequences of scientific and technological progress and human interaction with nature. The level of education and education of the community determines the internal state and culture, living conditions of people and, accordingly, the state of the economy, ecology and environment. That is why recently the formation of everyone's understanding of the essence of SRF has become especially important. 
The main components of this process are the formation of appropriate worldviews and values, the dominant is natural goods, awareness of reasonable needs and willingness to subordinate their interests to the laws of nature, the interests of society. SRF is designed to generate the meanings and values of life, through which, humanity is able to create conditions for sustainable development of civilization.

The main task of the SRF should be the formation of a new type of consciousness, on the basis of which there will be "... the humanization of nature and the naturalization of man." The new formed SRF, ecological and economic consciousness must logically include all the positives of previously known to mankind consciousness (magical, religious, scientific), ie to become comprehensive and syncretic in nature. Educational institutions in this model are designed to form in the younger generation a thorough knowledge of the laws of the world, the role of the environment in human life, its resources, opportunities to use natural resources (land, forests, water, air, minerals, etc.) in society.

That is why the SRS paradigm should be the basis of the national education system, which is being radically reformed today. This is due to the mission of the SRF and the needs of revolutionary changes in the organizational structure and content of modern general secondary and higher education. It is necessary to proceed from the fact that the level of ecological and economic culture of the individual and the community as a whole determine both the vectors of community development and the state of the natural environment. At the present stage of economic development of special importance in education is the process of forming a sustainable culture and worldview in each person, which include: change of consumer philosophy to realize the dominance of natural values over artificially created material, awareness of the need to subordinate their interests and needs.

SRF is beyond the power of a single subject teacher, it is a job multifaceted, continuous and developing, it is advisable to implement it comprehensively with the participation of primary school teachers, subject teachers of general secondary and higher education, it should be implemented on the principle of "lifelong learning". A special part of the SRF system is family upbringing, which lays the foundations of the worldview and value priorities and orientations of man. The system of preschool education is designed to form the motivational basis of adult consciousness. The main thing for school education is the formation of students' competencies necessary to achieve the global goals of sustainable development, proclaimed by the UN (UN General Assembly Resolution of September 25, 2015 № 70/1) and supported by Ukraine in accordance with the Decree of the President of Ukraine of September 30, 2019 № 722 "On the Sustainable Development Goals of Ukraine for the period up to 2030". In this context, the National SRF should be developed in the following areas and in the educational process to form:

- competence paradigm and innovative-humanistic perception of human life in nature;

- scientific knowledge about the relationship, interdependence and interaction of the possibilities of nature, the needs of society and its areas of production;

- awareness of the dominant value of natural goods for mankind;

- practical knowledge of the holistic scientific picture of the world, the relationship, interdependence and contradictions between the possibilities of nature and the needs of society;

- norms of sustainable behavior in the environment and among people, the need to communicate with nature;

- scientifically substantiated activity on protection and increase of natural resources.

Only the SRF and the ecologically and economically educated person will be able to help humanity develop in the right direction, according to the laws of nature. A consolidated SRF society will be able to look to the future with optimism. 


\section{Conclusions}

Mankind has the opportunity to choose, either the path of education for sustainable development, or the path to global catastrophe and self-destruction. Civilized nations are called to protect and multiply good, to establish by education and laws in society, public consciousness the highest spiritual values of human life. Only intelligence and continuous educational activity can create the conditions for sustainable development and the appropriate culture of society and translate its relationship with the environment on the path of intelligent coexistence. SRF is designed to form a responsible person who is ready for conscious action on the basis of acquired knowledge and established norms and rules of conduct in relation to the environment.

\section{References}

1. V.V. Khiminets, Education and time (2012)

2. O.E. Vysotska, Education for sustainable development (2011)

3. Education for Sustainable Development goals - learning objectives (UNESCO, 2017)

4. Global Action Programme (GAP) on Education for Sustainable Development (ESD): Goals and Objectives (UNESCO, 2018)

5. G. Michelsen, P.J. Wellsб A Decade of Progress on Education for Sustainable Development: Reflections from the UNESCO Chairs Programme (UNESCO, 2017)

6. Implementing SDGs-2030 in Ukraine: analysis of government strategies and public policy: Analytical Study (Kyiv, 2017)

7. I. Sinyakevych, Economy of Ukraine 12 69-77 (2010)

8. P.Günther Blue economy: 10 years, 100 innovations, 100 million jobs: Report of the Club of Rome. - RRF: Rick Reduction Foundation 2012

9. G. Pauli, The Blue Economy - 10 Years, 100 Innovations, 100 Million Jobs. New Mexico: Paradigm, 167-170 (2010)

10. V. Koval, Y. Polyezhayev, and A. Bezkhlibna, Balt. J. Econ. Stud. 4, 105 (2019)

11. I. Mikhno, V. Koval, G. Shvets, O. Garmatiuk, and R. Tamošiūnienè, Green Economy in Sustainable Development and Improvement of Resource Efficiency, Cent. Eur. Bus. Rev. 10, 99 (2021) 